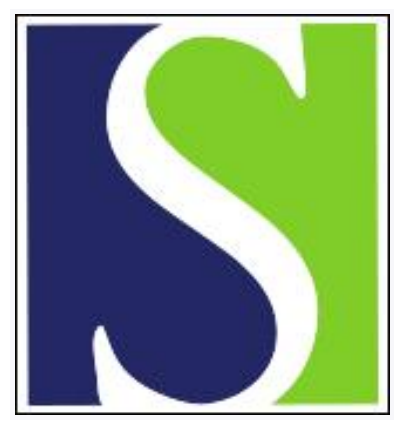

Scand J Work Environ Health 2018;44(4):432-435

https://doi.org/10.5271/sjweh.3738

Published online: 22 May 2018, Issue date: 01 Jul 2018

Night shift work and breast cancer risk: what do the meta-analyses tell us?

by Pahwa M, Labrèche F, Demers PA

This short communication examines the collective results from several recently published meta-analyses of night shift work and breast cancer risk. By summarizing and assessing the quality of these studies, opportunities for future epidemiologic research were identified along with the possible implications of meta-analyses on further evaluations of shift work with respect to breast cancer risk.

Affiliation: Paul A. Demers, Director, Occupational Cancer Research Centre, Cancer Care Ontario, 525 University Avenue, 3rd Floor, Toronto, Ontario, Canada, M5G $1 \times 7$. paul.demers@occupationalcancer.ca

Refers to the following text of the Journal: 2013;39(5):431-447

Key terms: breast cancer; cancer; hazard assessment; literature review; meta-analysis; night shift; night shift work; review; risk assessment; shift work; short communication

This article in PubMed: www.ncbi.nlm.nih.gov/pubmed/29790566 


\title{
Night shift work and breast cancer risk: what do the meta-analyses tell us?
}

\author{
by Manisha Pahwa, MPH, ${ }^{1}$ France Labrèche, PhD, ${ }^{2,3}$ Paul A Demers, PhD 1,4,5
}

\begin{abstract}
Pahwa M, Labrèche F, Demers PA. Night shift work and breast cancer risk: what do the meta-analyses tell us? Scand J Work Environ Health. 2018;44(4):432-435. doi:10.5271/sjweh.3738
\end{abstract}

\begin{abstract}
Objectives This paper aims to compare results, assess the quality, and discuss the implications of recently published meta-analyses of night shift work and breast cancer risk.

Methods A comprehensive search was conducted for meta-analyses published from 2007-2017 that included at least one pooled effect size (ES) for breast cancer associated with any night shift work exposure metric and were accompanied by a systematic literature review. Pooled ES from each meta-analysis were ascertained with a focus on ever/never exposure associations. Assessments of heterogeneity and publication bias were also extracted. The AMSTAR 2 checklist was used to evaluate quality.

Results Seven meta-analyses, published from 2013-2016, collectively included 30 cohort and case-control studies spanning 1996-2016. Five meta-analyses reported pooled ES for ever/never night shift work exposure; these ranged from 0.99 [95\% confidence interval (CI) $0.95-1.03, \mathrm{~N}=10$ cohort studies) to 1.40 (95\% CI $1.13-1.73$, $\mathrm{N}=9$ high quality studies). Estimates for duration, frequency, and cumulative night shift work exposure were scant and mostly not statistically significant. Meta-analyses of cohort, Asian, and more fully-adjusted studies generally resulted in lower pooled ES than case-control, European, American, or minimally-adjusted studies. Most reported statistically significant between-study heterogeneity. Publication bias was not evident in any of the meta-analyses. Only one meta-analysis was strong in critical quality domains.
\end{abstract}

Conclusions Fairly consistent elevated pooled ES were found for ever/never night shift work and breast cancer risk, but results for other shift work exposure metrics were inconclusive. Future evaluations of shift work should incorporate high quality meta-analyses that better appraise individual study quality.

Key terms hazard assessment; literature review; risk assessment; shift worker.

The potential association between shift work and breast cancer has been of longstanding interest to the global cancer research community in pursuit of more detailed and precise evidence regarding risk. Several meta-analyses synthesizing the growing body of epidemiological evidence on this topic have been published since the International Agency for Research on Cancer (IARC)'s 2007 evaluation of shift work involving circadian disruption as a probable carcinogen for the female breast (1). Since these meta-analyses have been published in a short time span, it is important to amass, summarize, and critically evaluate the methods and conclusions of these reports regarding night shift work as a potential breast carcinogen and to reflect on how they may be interpreted by scientists and policy-makers.
We conducted a search for and quality assessment of all meta-analyses on shift work and breast cancer risk, published in peer-reviewed journals, in order to synthesize results, compare and contrast findings. This exercise also allowed us to identify research gaps and discuss implications for potential future hazard and risk assessments of shift work involving circadian disruption.

\section{Methods}

We searched PubMed and Embase for meta-analyses and systematic literature reviews published between 2007 2017 without language restrictions. Meta-analyses had

\footnotetext{
1 Occupational Cancer Research Centre, Cancer Care Ontario, Toronto, Ontario, Canada.

2 Institut de recherche Robert-Sauvé en santé et en sécurité du travail, Montréal, Québec, Canada.

3 School of Public Health, Université de Montréal, Montréal, Québec, Canada.

4 Dalla Lana School of Public Health, University of Toronto, Toronto, Ontario, Canada.

5 CAREX Canada, Simon Fraser University, Burnaby, British Columbia, Canada.
}

Correspondence to: Paul A Demers, Director, Occupational Cancer Research Centre, Cancer Care Ontario, 525 University Avenue, 3rd Floor, Toronto, Ontario, Canada, M5G 1X7. [E-mail: paul.demers@occupationalcancer.ca] 
to report at least one pooled effect size (ES) for any metric of exposure to shift work involving nights and breast cancer incidence or mortality risk. The stated objectives, methods, and conclusions of each meta-analysis were summarized. Pooled ES from each meta-analysis were extracted and qualitatively compared by the following characteristics of reviewed studies: night shift work exposure metric and method of exposure assessment, occupation, study design, and adjustment for multiple covariates. Test results for heterogeneity and publication bias were extracted from each meta-analysis. Among the reviews that reported on a given metric, the results were deemed to be consistent if $\geq 50 \%$ of the pooled ES were statistically significant [ie, the $95 \%$ confidence interval (CI) for the pooled ES was >1.0]. Pooled ES for the ever versus never night shift work exposure metric were found in most meta-analyses and were used to reach the overall conclusions.

The AMSTAR 2 critical appraisal checklist was used to rate the methods and reporting of each metaanalysis (2) in order to identify their potential strengths and deficiencies and to explore opportunities for future research. In the checklist, the term "intervention" was replaced with "exposure to night shift work", and the term "comparator group" with "any shift work schedule aside from night shift work".

\section{Results}

Seven meta-analyses published between 2013-2016 collectively included 30 cohort and case-control studies spanning 1996-2016 (3-9). One meta-analysis accounted for variation in exposure assessment between studies (3); two explicitly sought to evaluate breast cancer pooled ES associated with long- versus short-term night shift work $(4,5)$; two included prospective studies only $(6,7)$; one focused on studies of breast cancer morbidity and allcause mortality (6); and one included studies of different sources of circadian disruption (8). In most meta-analyses $(3-7,9)$, multiple scientific databases were searched to identify eligible epidemiological studies.

Meta-analyses largely showed positive associations between ever versus never shift work involving nights and breast cancer risk. In the five meta-analyses that reported on this metric (4, 6-9), pooled ES ranged from $0.99(95 \%$ CI $0.95-1.03, \mathrm{~N}=10$ cohort studies) (8) to 1.40 (95\% CI 1.13-1.73, N=9 high quality studies] (9) (table 1). When studies were evaluated altogether or by certain study characteristics, over half of these positive associations were statistically significant (figure 1).

Some individual epidemiological studies have found elevated risks of breast cancer among women who worked shifts involving nights for thirty years or more
Table 1. Pooled effect sizes (ES) for breast cancer in association with ever versus never, duration, frequency, and cumulative night shift work exposure as reported in included meta-analyses of all studies [Cl=confidence interval; NR=not reported].

\begin{tabular}{|c|c|c|c|c|}
\hline $\begin{array}{l}\text { Meta-analysis first } \\
\text { author (year of } \\
\text { publication) }\end{array}$ & $\begin{array}{l}\text { Night shift work } \\
\text { exposure category }\end{array}$ & $\begin{array}{l}\text { Pooled } \\
\text { ES }\end{array}$ & $95 \% \mathrm{Cl}$ & $\begin{array}{l}\text { Studies (N) } \\
\text { included in } \\
\text { pooled ES }\end{array}$ \\
\hline \multicolumn{5}{|l|}{$\begin{array}{l}\text { Ever versus never } \\
\text { night shift work } \\
\text { exposure }\end{array}$} \\
\hline Jia et al (2013) a & Ever versus never & 1.20 & $1.08-1.33$ & 13 \\
\hline Kamdar et al (2013) ${ }^{\mathrm{b}}$ & Ever versus never & 1.21 & $1.00-1.47$ & 8 \\
\hline Travis et al (2016) ${ }^{\circ}$ & Ever versus never & 0.99 & $0.95-1.03$ & 10 \\
\hline Lin et al $(2015)^{\mathrm{c}}$ & Ever versus never & 1.06 & $1.01-1.10$ & 6 \\
\hline He et al (2015) & Ever versus never & 1.19 & $1.08-1.32$ & 15 \\
\hline \multicolumn{5}{|l|}{$\begin{array}{l}\text { Duration of night shift } \\
\text { work exposure }\end{array}$} \\
\hline ljaz et al (2013) a & Per 5-year increment & 1.05 & $1.01-1.10$ & 12 \\
\hline \multirow[t]{2}{*}{ Kamdar et al (2013) b } & $\begin{array}{l}<8 \text { years versus never } \\
\text { night shift work }\end{array}$ & 1.13 & $0.97-1.32$ & 13 \\
\hline & $\begin{array}{l}\geq 8 \text { years versus never } \\
\text { night shift work }\end{array}$ & 1.04 & $0.92-1.18$ & 9 \\
\hline Wang et al (2013) a & Per 5-year increment & 1.03 & $1.01-1.05$ & 10 \\
\hline Jia et al (2013) a & $\begin{array}{l}\geq 15 \text { years versus never } \\
\text { night shift work }\end{array}$ & 1.15 & $1.03-1.29$ & 8 \\
\hline \multirow[t]{2}{*}{ Travis et al (2016) ${ }^{c}$} & $\begin{array}{l}\geq 20 \text { years versus never } \\
\text { night shift work }\end{array}$ & 1.01 & $0.93-1.10$ & 8 \\
\hline & $\begin{array}{c}\geq 30 \text { years versus never } \\
\text { night shift work }\end{array}$ & 1.00 & $0.87-1.14$ & 4 \\
\hline \multirow[t]{5}{*}{ Lin et al (2015) c } & Per 5-year increment & 1.02 & $1.00-1.04$ & 4 \\
\hline & $\begin{array}{l}<5 \text { years night shift work } \\
\text { versus daytime work }\end{array}$ & 1.03 & $0.97-1.09$ & 4 \\
\hline & $\begin{array}{c}5-10 \text { years night shift } \\
\text { work }\end{array}$ & 1.03 & $1.01-1.04$ & 4 \\
\hline & $\begin{array}{l}\text { 10-20 years night shift } \\
\text { work }\end{array}$ & 1.07 & $1.01-1.14$ & 4 \\
\hline & $\begin{array}{c}>20 \text { years night shift } \\
\text { work }\end{array}$ & 1.09 & $1.01-1.17$ & 4 \\
\hline $\begin{array}{l}\text { He et al (2015) } \\
\text { Frequency of night } \\
\text { shift work exposure }\end{array}$ & Per 10-year increment & 1.06 & $0.98-1.15$ & NR \\
\hline Wang et al (2013) a & $\begin{array}{l}\text { Per 3-night shifts/month } \\
\text { increment }\end{array}$ & 1.02 & $0.97-1.09$ & 3 \\
\hline \multicolumn{5}{|l|}{$\begin{array}{l}\text { Cumulative night shift } \\
\text { work exposure }\end{array}$} \\
\hline ljaz et al (2013) ${ }^{\mathrm{a}}$ & $\begin{array}{l}\text { Per 300-night shifts } \\
\text { increment }\end{array}$ & 1.04 & $1.00-1.10$ & 8 \\
\hline Wang et al (2013) a & $\begin{array}{l}\text { Per 500-night shifts } \\
\text { increment }\end{array}$ & 1.13 & $1.07-1.21$ & 4 \\
\hline
\end{tabular}

${ }^{a}$ Meta-analysis included studies of military crew.

${ }^{\mathrm{b}}$ Meta-analysis included studies of airline crew.

'Pooled ES for cohort studies only.

$(10,11)$. However, pooled ES for duration of night shift work exposure largely hovered around the null, and were not statistically significant, as reported in seven metaanalyses that calculated breast cancer risks for categorical or ordinal metrics of number of years of night shift work (3-9). Only one meta-analysis included a pooled ES for frequency (per three night shifts/month) (5) and two included pooled ES for cumulative lifetime night shift exposure $(3,5)$ and breast cancer risk; nearly all of these associations were null (table 1). Few reviews reported pooled ES for other exposure metrics. Of the reviews that did, the pooled ES were not directly comparable. Some were reported on as continuous (eg, breast cancer risk associated with every 5 years of shift work) and cat- 


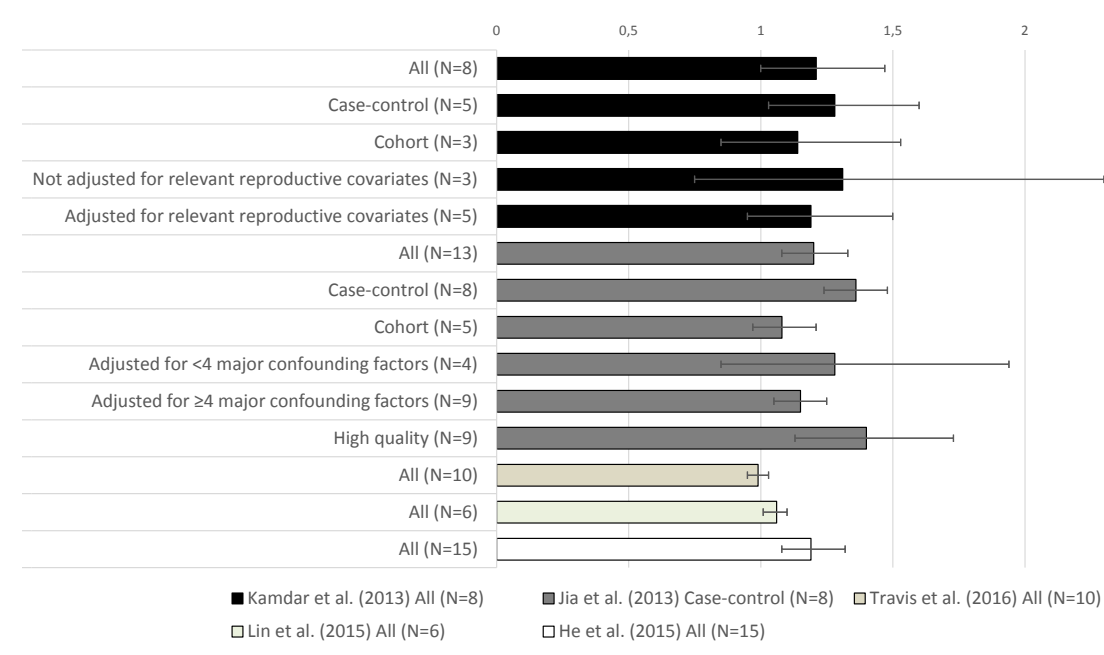

Figure 1. Pooled effect sizes [ES (horizontal axis)] for ever versus never shift work involving nights and breast cancer riskin meta-analysesthat reported on this association. Error bars: $95 \%$ confidence intervals for pooled ES * Statistically significant pooled ES. egorical (eg, breast cancer risk associated with $>15$ years of shift work) metrics. The respective intervals of these continuous and categorical metrics also differed between reviews. For these reasons, it was not possible to conclude about potential associations with breast cancer risk.

Considering exposure assessment of ever versus never night shift work, the pooled ES of breast cancer that used census or job-exposure-matrix-derived data (pooled $\mathrm{ES}=1.35,95 \%$ CI 0.97-1.89, four studies) was higher than the pooled ES that used self-reported exposure data (pooled $\mathrm{ES}=1.14,95 \%$ CI 0.89-1.47, three studies) and the pooled ES that used a combination of both exposure assessment approaches (pooled ES=1.00, 95\% CI 0.90-1.47, one study) (4).

Few meta-analyses evaluated aggregate risks by occupation $(4,9)$. Among nurses, there were slight excesses of breast cancer associated with ever versus never night shift work (pooled $\mathrm{ES}=1.15$, 95\% CI 1.03-1.29, $\mathrm{N}=4$ studies) (9) and eight or more years versus never night shift work (pooled $\mathrm{ES}=1.14,95 \% \mathrm{CI}$ 1.01-1.28, N=4 studies) (4). Meta-analyses of cohort $(3-5,8,9)$, and more fully-adjusted studies $(4,9)$ generally resulted in lower pooled ES than case-control (3-5, $8,9)$, or minimally-adjusted studies $(4,9)$.

Most meta-analyses were conducted using random effects models due to statistically significant betweenstudy heterogeneity, reported as $\mathrm{I}^{2}$ values that were $>50 \%$ in four papers $(3,4,8,9)$. Publication bias was not evident in any meta-analysis. Five meta-analyses appraised the quality of reviewed studies using different tools. The quality of these studies was generally rated as low $(3-5,8,9)$. One meta-analysis included a sub-group analysis restricted to nine high-quality studies (9). Risk of bias was evaluated in two meta-analyses $(3,5)$ and reported as moderate overall in one paper (3).

Using the AMSTAR 2 quality assessment checklist, only Ijaz et al's meta-analysis (3) was rated as high quality. The authors appropriately addressed several critical domains in the checklist; most importantly, they assessed and discussed the potential impact of risk of bias (using a standardized tool). The authors also cited a protocol established prior to executing the review, reported funding sources in individual epidemiological studies, and provided a list of excluded studies with reasons for exclusion. Additional deficits of the other reviews were potentially biased study selection and the study selection and data extraction by only one author.

\section{Discussion}

In this qualitative evaluation of seven meta-analyses, there was fairly consistent evidence for a positive association between ever versus never night shift work and breast cancer risk. However, confidence in the results of these meta-analyses was found to be low to moderate primarily because they did not include risk of bias assessment. There were insufficient and incomparable data on duration, frequency, and cumulative lifetime night shift work exposure and breast cancer risk. Like the authors of all papers, we acknowledge and agree that further high-quality research is needed.

Results from meta-analyses need to be interpreted with caution since the studies and relative risks that they reviewed were not directly comparable to each other and generally of low quality. As expected, epidemiological studies done in various settings and among diverse populations show substantial methodological variation. A major source of heterogeneity in meta-analyses was the varying methods used to define and assess night shift work exposure in reviewed studies. Meta-analyses of ever versus never night shift work likely yielded a range of results partly owing to this fact. Incomparable results found for other night shift work exposure metrics could also be somewhat due to differences in exposure 
assessment methods between studies. There is a need for several objective and standard approaches to capture relevant aspects of shift work in subsequent investigations. There was also inconsistent adjustment for known and potentially confounding variables of the association between shift work and breast cancer in the individual epidemiological studies included in meta-analyses, as well as in the methods used to ascertain covariate information. Lastly, the possibility of some residual bias cannot be ruled out. To capture the greatest number of epidemiological studies, it would be prudent for future systematic reviews to include publications in all languages, when possible; case-control and cohort designs; reports on workers in most occupations and industries; and papers that state a clear definition of "night shift work" in their evaluations of breast cancer risk.

Shift work involving circadian disruption is a priority for evaluation by the IARC Monographs program by the year 2019 (12). Whether meta-analyses published to date may help tip the scale towards a definite human carcinogen classification or not hinges on a meticulous and cautious review of their selection criteria, statistical analyses, and quality. The present review of seven meta-analyses indicates consistent associations between ever versus never night shift work and breast cancer risk, but with critical concerns regarding their quality and inadequate and incomparable information for duration, frequency, and cumulative lifetime exposure to night shift work. Important methodological advancements in both meta-analyses and individual epidemiological studies are crucial for gaining a better understanding of its potential impact on breast cancer risk. Any future evaluations of the carcinogenic potential or cancer risks of shift work need to consider results from high quality meta-analyses that exhaustively review all available studies, with better assessment of individual study quality.

\section{Acknolwedgments}

The authors acknowledge institutional support from the Canadian Cancer Society, Ontario Ministry of Labor, and Cancer Care Ontario.

The authors declare no conflicts of interest.

\section{References}

1. International Agency for Research on Cancer (IARC). IARC Monographs on the Evaluation of Carcinogenic Risks to Humans. Volume 98: Painting, Firefighting, and Shiftwork. WHO Press, Lyon, 2010.
2. Shea BJ, Reeves BC, Wells G, Thuku M, Hamel C, Moran $J$ et al AMSTAR 2: a critical appraisal tool for systematic reviews that include randomised or non-randomised studies of healthcare interventions, or both. BMJ 2017 Sep;358:j4008. http://dx.doi.org/10.1136/bmj.j4008.

3. Ijaz S, Verbeek J, Seidler A, Lindbohm ML, Ojajärvi A, Orsini $\mathrm{N}$ et al Night-shift work and breast cancer--a systematic review and meta-analysis. Scand J Work Environ Health 2013 Sep;39(5):431-47. http://dx.doi.org/10.5271/ sjweh.3371.

4. Kamdar BB, Tergas AI, Mateen FJ, Bhayani NH, Oh J. Night-shift work and risk of breast cancer: a systematic review and meta-analysis. Breast Cancer Res Treat 2013 Feb;138(1):291-301. http://dx.doi.org/10.1007/s10549-0132433-1.

5. Wang F, Yeung KL, Chan WC, Kwok CC, Leung SL, $\mathrm{Wu} \mathrm{C}$ et al A meta-analysis on dose-response relationship between night shift work and the risk of breast cancer. Ann Oncol 2013 Nov;24(11):2724-32. http://dx.doi.org/10.1093/ annonc/mdt283.

6. Lin X, Chen W, Wei F, Ying M, Wei W, Xie X. Nightshift work increases morbidity of breast cancer and allcause mortality: a meta-analysis of 16 prospective cohort studies. Sleep Med 2015 Nov;16(11):1381-7. http://dx.doi. org/10.1016/j.sleep.2015.02.543.

7. Travis RC, Balkwill A, Fensom GK, Appleby PN, Reeves GK, Wang XS et al Night Shift Work and Breast Cancer Incidence: Three Prospective Studies and Meta-analysis of Published Studies. J Natl Cancer Inst 2016 Oct;108(12). http://dx.doi.org/10.1093/jnci/djw169.

8. He C, Anand ST, Ebell MH, Vena JE, Robb SW. Circadian disrupting exposures and breast cancer risk: a meta-analysis. Int Arch Occup Environ Health 2015 Jul;88(5):533-47. http://dx.doi.org/10.1007/s00420-014-0986-X.

9. Jia Y, Lu Y, Wu K, Lin Q, Shen W, Zhu M et al Does night work increase the risk of breast cancer? A systematic review and meta-analysis of epidemiological studies. Cancer Epidemiol 2013 Jun;37(3):197-206. http://dx.doi. org/10.1016/j.canep.2013.01.005.

10. Grundy A, Richardson H, Burstyn I, Lohrisch C, SenGupta SK, Lai AS et al Increased risk of breast cancer associated with long-term shift work in Canada. Occup Environ Med 2013 Dec;70(12):831-8. http://dx.doi.org/10.1136/ oemed-2013-101482.

11. Schernhammer ES, Laden F, Speizer FE, Willett WC, Hunter DJ, Kawachi I et al Rotating night shifts and risk of breast cancer in women participating in the nurses' health study. J Natl Cancer Inst 2001 Oct;93(20):1563-8. http:// dx.doi.org/10.1093/jnci/93.20.1563.

12. Straif K, Loomis D, Guyton K, Grosse Y, Lauby-Secretan B, El Ghissassi F et al Future priorities for the IARC Monographs. Lancet Oncol 2014;15:683-4. http://dx.doi. org/10.1016/S1470-2045(14)70168-8.

Received for publication: 24 August 2017 